\title{
An Exploratory Study of Product Development in Emerging Economies: Evidence from Medical Device Testing in India \\ _ _ An Exploratory Study of Product Development in Emerging Economies: \\ Evidence from Medical Device Testing in India
} (3)

(1)

ren

\section{- Abstract -}

Recent research has studied innovation in emerging economies. However, micro-level product development processes in these economies are relatively unexplored, and the mechanisms by which the emerging economy context might affect such processes are still unclear. In this paper, we explore the testing routines fundamental to product development in one emerging economy. Based on an exploratory field study of medical device development projects in India, we observe the frequent, iterative testing of prototypes in clinical settings and investigate the related learning process. The observed testing approach is distinctly different from the comparatively linear and sequential approach adopted by medical device development teams in developed countries like the US. Further, we suggest that such testing is feasible in India because of the prevailing regulatory flexibility, the cognitive orientation of device development practitioners and the normative orientation of medical professionals.

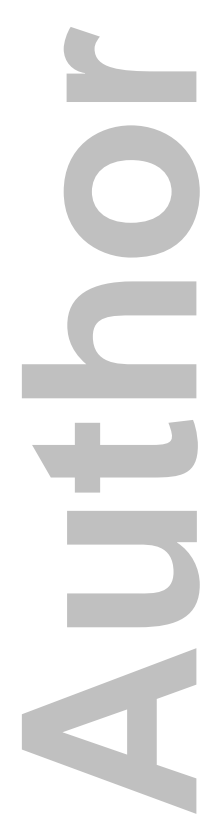

This is the author manuscript accepted for publication and has undergone full peer review but has not been through the copyediting, typesetting, pagination and proofreading process, which may lead to differences between this version and the Version of record. Please cite this article as doi:10.1111/ radm.12324. 


\section{Introduction}

Recent years have seen an increased focus on innovation in emerging economies. This is not surprising, as many of these countries offer new markets and growth opportunities for both local and international businesses (London and Hart, 2004; Prahalad and Hammond, 2002). However, while recent discussions on resource-constrained innovation (Ray and Ray, 2010) and frugal innovation (The Economist, 2010; Zeschky, Widenmayer, and Gassmann, 2011) explain how and why the context of emerging economies (lower income levels, lack of electricity, spare parts, trained man-power etc.) influences product design (i.e., features, usability, and pricing), surprisingly few studies have investigated micro-level product development processes in emerging economies or the influence of the external context on such processes.

The above gap is particularly relevant given the unique context of emerging economies. Research has highlighted that many emerging economies are characterized by high economic and political uncertainty, institutional complexity, and within-country diversity. Perhaps even more challenging for product development are the lack of functioning institutions, the limited availability of skilled human resources, the absence of stable regulations and clear policies, and the under-developed research ecosystem and infrastructure (Khanna et al., 2005; Mair et al., 2012; Mair and Marti, 2009; Peng et al., 2008; Sheth, 2011). Collectively these factors pose a serious challenge for developing new products in these locations (Burgess and Steenkamp, 2006; Luo, 2001; Peng et al., 2008; Wright et al., 2005). Nevertheless, firms, both local and international, operating in emerging economies have developed numerous successful frugal innovations, including mobile money, low-cost medical devices, a car costing US\$2000, and low-cost cardiac and cataract surgeries (Dubiel and Ernst, 2013; Ernst et al., 2014; Prahalad, 2012; The Economist, 2010).

This leads us to the motivating question of this paper: How do product development teams in the emerging economies manage critical processes while developing contextappropriate products for the local market? Given the un(der)-explored nature of our question, we adopted an exploratory, field-based and inductive approach to study critical product development routines in medical device development projects in India.

In this paper, we report our observations on prototype-based testing approaches, which are fundamental to product development efforts and project performance (Brown, 2009; 
Thomke, 1998; Thomke, von Hippel, and Franke, 1998). First, we highlight the challenges arising from contextual factors such as under-developed R\&D infrastructure and ecosystems, limited involvement of physicians in medical device development, and limited experience on the part of R\&D practitioners. Given these constraints, the medical device development teams engaged in rapid, iterative, high-fidelity prototype testing right from the project onset; the observed iterative testing approach differs from the comparatively linear and sequential testing during medical device development in developed countries like the US. Second, we suggest that the approach observed in India was enabled by elements of the emerging economy context: India's regulatory flexibility, the normative orientation of physicians, and the cognitive orientation of device development practitioners. Our exploratory study thus highlights the dual effect of context in emerging economies on product development, as it illustrates how different aspects of the context both deter and assist the design uncertainty resolution process. Third, our study highlights how product development efforts in India benefitted from the learning derived from the observed testing approach.

\section{Background}

\subsection{Prototyping in Product Development}

Studies (Iansiti, 1997; Smith and Eppinger, 1997; Thomke, 1997) have shown that product development efforts consist of extensive testing that supports an underlying iterative trial and error problem-solving process. At the outset, one or more potential solutions are identified and appropriate prototypes developed. The prototypes are then tested against a set of predefined acceptance criteria. Because the optimal solution might not be among the initial alternatives, the learning from these tests is used to develop the next set of solutions and prototypes. The incremental learning at each step of the prototyping process drives the progress towards identifying the preferred solution (Bogers and Horst, 2014; Verganti, 1997; Thomke and Fujimoto, 2000).

Research has also suggested that prototyping not only helps determine the final product design based on predefined specifications, but can also help to determine the specifications themselves (Terwiesch and Loch, 2004). This is especially true for novel products for which prior experience and existing assets are of little use. Related to this, the involvement of customers in the prototyping process is encouraged (Callahan and Lasry, 2004); 
especially in the early stages of the development of novel products. Naturally, prototyping is a fundamental aspect of organizational innovation (Mascitelli, 2000; Schrage, 2000). Recent research (Bogers and Horst, 2014) has highlighted that collaboration between different stakeholders across functional, organizational, and hierarchical boundaries can improve the prototyping-driven problem-solving process.

Research on testing has also noted that the sooner any new information becomes available, the greater its usefulness in any product or process development effort (Krishnan, Eppinger, and Whitney, 1997; Terwiesch, Loch, and Meyer, 1998; Thomke and Fujimoto, 2000), because the cost and time required to make changes to any design increase rapidly as a project progresses. Naturally developers prefer tests that generate critical information early (Boehm, Gray, and Seewaldt, 1984). However, such testing is often expensive, timeconsuming, or infeasible given limited access to users and the product use environment. Finally, any learning resulting from incompleteness (or low fidelity) of early-stage testing models can lead to unexpected errors when the design is eventually tried out in the real environment (Pisano, 1996).

The research on prototype-based testing, though vast and rich in insights, has largely ignored the possibility of influence of the external context. In this paper, we explore how the emerging economy context affects prototype-based testing routines during product development. Moreover, research on prototype-based testing (Pisano, 1996; Thomke, 1998; Thomke and Bell, 2001) suggests that relevant R\&D staff experience, knowledge, capabilities, and infrastructure matter. Such resources cannot be taken for granted in emerging economies. Resource constraints for prototyping in emerging economies also result from a price-sensitive customer base and the need to minimize product development costs. This, in turn, can make prototyping even more difficult. Collectively, these challenges call for studies that explore prototyping in product development initiatives in emerging economies.

\subsection{Product Development in Emerging Markets}

Emerging economies are today recognized as sources of innovative new products that aim to deliver high value at low costs (Luo, 2001; Govindarajan and Ramamurti, 2011, Zeschky, Widenmayer, and Gassmann, 2011). These products tend to be distinctly different from developed country products in terms of price, features, ease of use, ease of maintenance, etc. (Lee et al., 2011; Prahalad, 2012). This is not surprising: emerging market contexts are 
characterized by significantly lower per capita income, distinct customer requirements and preferences, limited availability of qualified technicians, etc.

Practitioners and researchers have referred to these emerging-economy solutions using a broad set of terms like cost innovation (Williamson, 2010), good-enough innovation (Gadiesh, Leung, and Vestring, 2007; Hang, Cheng, and Subramanian, 2010), frugal innovation (Zeschky, Widenmayer, and Gassmann, 2011; The Economist, 2010), and resource-constraint innovation (Ray and Ray, 2010). Research (Zeschky, Winterhalter, and Gassmann, 2014) has argued that though these innovation types are fundamentally different, they all offer contextappropriate functionalities at lower costs in comparison to existing developed-country solutions. Interestingly, both local organizations in the emerging economies and subsidiaries of international organizations located in these geographies engage in such innovation efforts, given the opportunity to serve large yet previously un(der)-served markets. That said, the subsidiary of an international organization needs significant autonomy and local-market focus to develop these solutions, given the international organization's natural bias towards affluent segments in developed countries (Zeschky, Widenmayer, and Gassmann, 2011). Furthermore, recent research (Winterhalter et al., 2017) has explored the importance of designing effective business models for frugal innovations developed in emerging economies and highlighted related mechanisms related to value proposition, value creation, and value appropriation. Finally, there is increasing recognition that some of the innovations from emerging economies may eventually be adopted by developed countries, a phenomenon referred to as reverse innovation (Govindarajan and Ramamurti, 2011; Zeschky, Winterhalter, and Gassmann 2014). This is significant considering not only that the innovative products developed in emerging economies offer unprecedented value propositions to a large base of previously un(der)-served customers, but also that these solutions might disrupt existing markets in developed countries. Interestingly, while there has been much discussion of emerging economy innovations (i.e., product features, types of innovation, business models, global diffusion), surprisingly few studies have investigated micro-level product development processes in these emerging economies or the influence of the emerging economy context on product development practices. This is an important gap, given that (1) the design of these emerging economy innovations is not known ex-ante and (2) context-appropriate products developed in emerging economies have local and global significance. Further, the need to explore the processes 
underlying the development of innovative products for emerging economies is exacerbated given the product development challenges arising from the emerging economy context: lack of functioning institutions, the limited availability of skilled human resources, the absence of stable regulations and clear policies, and the under-developed research ecosystem and infrastructure (Khanna et al., 2005; Mair et al., 2012; Mair and Marti, 2009; Peng et al., 2008; Sheth, 2011).

\section{Research Method}

\subsection{Research Setting}

India's economic growth over the last two decades has motivated both international medical device MNCs and local startups to focus on the India market. This, in turn, has resulted in the development of affordable, context-appropriate, and effective medical devices. The development of these medical devices for the India market offers a rich setting for us to explore our research question: How do product development teams in the emerging economies manage critical processes while developing context-appropriate products for the local market? Given our lack of understanding of the processes underlying the development of emerging-economy innovations, we used an inductive, in-depth, and field-based approach that is appropriate for developing new theory and elaborating previously under-explored theory (Eisenhardt, 1989). The research, conducted over several months between 2012 and 2014, consisted of iteratively collecting and analyzing data.

\subsection{Data Collection}

In early 2012, based on discussions with physicians, academics, and management consultants and a review of relevant articles and websites, we identified six successful innovative medical devices developed in India specifically for the local market. The organizations involved in developing these devices included both local R\&D centers of developed-country MNCs and domestic businesses; the mix of organizations arising out of our theoretical sampling approach was consistent with our prior understanding of the range of organizations involved in developing context-specific products for emerging economies. We contacted the six organizations to study their product development strategies and practices for the India market. One of the organizations couldn't participate because it lacked the time and 
resources to coordinate our visits. We conducted 11 exploratory interviews with the remaining five organizations.

An analysis of these preliminary interviews led us to request further access to study details of the development processes of the specific medical devices identified initially. At this stage, two of the organizations declined further participation in our study, citing confidentiality concerns and lack of management bandwidth. At each of the remaining three organizations (the Indian R\&D center of a US MNC, a large tertiary care hospital, and a medical device startup), we collected detailed data on the recently completed development project of the identified medical device. Specifically, for each project we reviewed project documents to collect data on project scope, product description, team, timeline, activities, project plans, product testing, etc. The documents on testing included detailed information on prototyping and testing, its process and learning, and follow-up activities. In addition to the archival data collection and field notes, we conducted an additional 19 semi-structured interviews at the three organizations. At each one, we interviewed the product development head, the project manager, and other team members. Interviews typically lasted 30 minutes to 90 minutes, and some individuals were interviewed multiple times as we worked through the iterative process of data collection, analysis, comparison, and insight development. To reduce the risk of information bias, we questioned multiple individuals on overlapping topics and ensured a high level of consensus on all factual matters. An overview of the data collection efforts is presented in Table 1.

\section{- INSERT TABLE 1 HERE -}

\subsection{Data Analysis}

We developed detailed single longitudinal case studies (Yin, 2013) for each of the device development projects. Based on discussions with the organizations regarding the sensitivity of the information, we anonymized company- and project-specific information.

Following the basic tenets of Miles and Huberman (1994), we analyzed the data of each individual case to generate insights and themes and then went back and forth between the emerging themes and data for further refinement. As our analysis progressed, we explored the interrelations amongst the emerging themes and compared them to published research findings. This systematic approach allowed us to determine the dominant themes and mechanisms at 
work. Finally, we conducted a systematic comparison across the cases using tabular patternmatching, which revealed the highly-iterative, high-fidelity prototype testing routines as critical and common activities across the projects. Furthermore, the comparison across cases allowed us to identify three contextual dimensions (discussed in the Findings section) that seemed particularly significant. It is important to note here that given the differences among the three organizations and their products, we noticed expected differences in product type, product complexity, team sizes, decision-making logic, etc. However, the consistency of the observed prototype-based testing approach across the different projects and organizations and the importance of such testing in the success of the product development effort is significant and supports the validity of our findings. In other words, our findings are based on strong and important commonalities across projects in the development of different medical devices at different types of organizations.

Finally, we discussed our findings with all five participating organizations. These discussions allowed us to both validate and deepen our findings. Further, by early 2014, we also recognized that the testing processes observed were significantly different from the standardized testing practices mandated by the Federal Drug Authority (FDA) in the US. This led us to interact with two medical device development experts in the US and review publicly available material on FDA-mandated processes to validate the differences across countries and explore potential implications.

\section{Case Summaries}

Below we present a brief overview of the three projects to illustrate the testing approach adopted by the teams and the logic that underpins the core argument of this paper.

\subsection{Case 1: Affordable Ophthalmology Device Developed by Indian Startup}

As a country, India has a large number of blind people, and a significant proportion of these blindness cases are preventable with timely detection and intervention. A medical device startup located in Delhi sought to develop an affordable, non-invasive, and rugged ophthalmology device that could develop an image of the anterior (cornea) and posterior (retina) surface of the eye and thus check for common eye problems related to cataracts, glaucoma, diabetes, etc. The primary design issues to be addressed during the project involved ensuring a high image quality for diagnostic purposes and determining the external physical 
form to ensure ease of use, ruggedness, and acceptability by both physicians and patients. The team had the opportunity to partner with a leading ophthalmology hospital in India in the early stages of development; the hospital was supportive of the development effort as the device would address the needs of the under-served population in rural India. The startup team, consisting primarily of business and engineering talent, had limited experience and expertise in ophthalmology and approached the development effort as a series of iterative trials on the patients at the hospital.

During each trial, the ophthalmologists at the hospital took the eye images of 20 or more eye patients using the latest prototype and provided feedback to the startup team on the quality of the images for clinical diagnosis and how the images compared with those from devices by high-end manufacturers. Given the low risk to the patients, Institutional Review Board (IRB) and patient consent were not deemed necessary. To ensure that the startup team had rich feedback to develop a robust device, the ophthalmologists provided image feedback for a variety of eye diseases. Further, the ophthalmologists used the prototype in a rural eye camp to test the operability of the device in the field. Given the non-invasive nature of the device, IRB approval and patient consent were not deemed necessary here either. In all, six trials were conducted with the hospital, and the startup team used the learning from these iterations to improve the prototype for subsequent testing. The team was able to launch the device at the end of the first year of the development effort. Subsequently, the team did a small-scale clinical trial to establish that the device's performance was comparable to that of the high-end products in the market. Post-launch, the device proved to be extremely effective and popular and was used widely in both India and other developing countries.

\subsection{Case 2: ICU Software Solution Developed by Tertiary Care Hospital}

A large tertiary care hospital located in Mumbai partnered with a software services company to develop a software solution for enhancing critical patient care in the intensive care unit (ICU). The solution would not only result in improved patient-condition tracking and careplanning but also would help address the challenge arising from the unavailability of experienced and competent nurses in the ICU across hospitals in India. An initial prototype, a base version, was designed based on interaction with and observation of physicians and nurses in the ICU, and the solution was installed for two ICU patient beds in January 2011 for earlystage testing. Members of the development were positioned in the ICU to observe the clinical 
staff operating the installed solution and obtain user feedback. Based on these observations and interactions, decisions were made regarding additional features and necessary modifications.

New features were released periodically to the software installed at the ICU and additional feedback was obtained from the clinical staff throughout the process. One of the team members observed, "Whenever we released new features, we were there to observe if there were any issues related to the overall system, the software or if the challenges were related to nurse training or the learning curve. It was a learning process all the way."

To ensure patient safety, an additional nurse was assigned to the ICU patient with the prototype solution to ensure that established ICU practices were followed in parallel and paper documentation of the patient's information was maintained for all clinical tasks. Given that the risk to the patient was deemed negligible because of these measures and there was no direct intervention in patient treatment based on the prototype, formal IRB approval and patient consent were not considered necessary.

As the solution improved over time, it was deployed on additional patient beds. The increased usage by other physicians and nurses and the variation in patient profiles and conditions led to further learning. By December 2011, after six iterations, the solution was stable and feature-rich and was launched across all critical patients at the hospital, as well as in partnering hospitals.

\subsection{Case 3: Orthopedic Surgical Jig Development by US MNC R\&D Center in India}

The R\&D center of a US-headquartered medical devices company identified an opportunity to develop an orthopedic surgical jig for the Indian market in late 2010. The idea was to offer a locally-developed, affordable, customized surgical jig specific to a knee-surgery patient based on a scan of the patient's femur and tibia bone prior to the knee surgery. This jig, manufactured based on the patient's specific bone anatomy and deformities, would allow surgeons, especially the less-experienced ones, to accurately and rapidly determine the critical bone cuts during the surgery and would improve surgical outcomes.

The MNC's standardized product development processes in the US required that earlystage validation and refinements for developing the device be performed in a cadaver lab. Cadaver knee bones would be scanned to design and develop jig prototypes, which would then be tested on cadavers. Typically, multiple cadaver sessions would be conducted iteratively as the team refined the process and product design. However, the team in India was unable to 
locate a cadaver lab for partnering. Consequently, the team worked with three senior surgeons at different hospitals to iteratively test the product prototype on patients undergoing knee implant surgery so that the team could simultaneously refine the design and establish feasibility.

For testing, the team would develop a physical prototype of the jig using biocompatible material based on scans of the patient performed prior to the surgery. During the surgery, surgeon would place the prototype jig on the bone of the patient to test whether the jig's design, form, and fit on bone surface were appropriate and used an external computerassisted system to check whether the cutting plane suggested by the jig was accurate. Once the surgeons placed the prototype on the patient bone in the operating room, they could identify design-related issues and suggest necessary design revisions. The surgeon would then set the prototype aside and proceed with the surgical activities by using the traditional method, which was more invasive, required more operating time, posed higher risks, and involved longer postop recovery periods. Post-surgery, the surgeon would share his observations with the project team and the team, in turn, would made jig design and process-related refinements prior to the next iteration.

To ensure patient safety, the team designed the testing jigs so that they could not be used for any surgical processes, and the surgeons agreed to not use the jigs for any surgical decisions. Given that the testing approach was considered low-risk and had no impact on treatment protocols or outcomes, the team and the surgeons decided not to seek IRB approval or patient consent. A total of 15 knee implant testing sessions were conducted by the three surgeons over an 8-month period (August 2011 - March 2012). In June 2012, the team commenced a limited clinical trial in India. The results from the clinical trial were positive and the product was successfully launched in India in December 2012.

\section{Findings}

In this section, we discuss three key findings from our field study. First, we highlight the product development challenges arising from multiple contextual factors in emerging economies like India: under-developed R\&D infrastructure and ecosystem, lack of physician involvement, limited experience on the part of R\&D practitioners, etc. In the presence of such challenges, the project teams in India engaged in iterative, high-fidelity prototype testing in 
clinical settings from the early stages of the projects. We note that this approach was different from the comparatively linear and sequential testing approach adopted by medical device development teams in developed countries like the US. Second, we suggest that the observed iterative testing approach in India was enabled by elements of the emerging economy context, specifically the prevailing regulatory flexibility in India and the normative and cognitive orientations of medical device professionals and development practitioners, respectively. Third, we discuss how the product development efforts benefitted from the learning derived from the iterative testing approach in high-fidelity clinical settings and suggest that in the absence of such learning, the projects would likely not have been feasible.

In summary, our study explores why and how medical device development teams adopt an iterative testing approach while developing context-appropriate products for emerging economies. A summary of these findings is presented in Table 2 below.

\section{- Insert Table 2 here -}

\subsection{Constraints Set by Context: Experience and Ecosystem}

The emerging market context creates unique constraints for product development teams. Both the hospital and the startup had limited development experience in medical devices and lacked specialized technical skills. Moreover, the region as a whole had few experienced people, which in turn posed challenges for the MNC R\&D Center. A senior member of the software services company working on the ICU software project commented, "We understand technology. But it is not possible for us to develop such a complex device as we do not have the domain knowledge and the experience of developing similar medical devices." On a similar note, the founder of the ophthalmology startup noted, "We were motivated to develop the device as there was a real need in the market. However, none of us in the team had developed medical devices. We are a bunch of engineers and knew little about ophthalmology when we started." One of the team members observed, "Though we could do internal testing of images (using the eyes of the team members), who is going to review our images? How do we know whether it is a good image? What is diabetic retinopathy? We don't even know that. How do we screen for it? We were not sure." 
The MNC R\&D center could not locate a cadaver lab for the initial testing and validation of the proposed surgical jig. In India, the majority of device development work focuses on low-complexity devices that do not require cadavers, and consequently there is no established network of cadaver labs, as there is in the US. The project manager observed, "We were disappointed as we could not find a cadaver lab we could work with. We were not able to move forward. We had done some saw-bone sessions inside our lab but that did not give us a good feel for whether the product would work." The ecosystem in India was not sufficiently mature to enable the kind of external collaborations the organization used in the US. The absence of engineering staff with experience in developing similar orthopedic devices made the unavailability of a cadaver lab an even greater obstacle, as a lab would have allowed the team to experiment and learn quickly, especially in the initial stages.

Proposition 1: An emerging economy's $R \& D$ ecosystem (like India 's) imposes unique constraints on medical device development initiatives managed by both international and local organizations.

In the presence of these challenges, the product development teams adopted an iterative prototype-based testing approach in a high-fidelity clinical setting where medical practitioners were engaged in treating patients. The initial prototype was introduced to the clinical setting early in the project, and prototypes in future rounds were designed based on learning from prior testing. For example, a team member at the ophthalmology device project observed, "The first time we went to the hospital we took with us a presentation showing the product architecture. At this time, we also had images of the eye we had taken using the device. We got some feedback on how to improve the image quality and patient comfort. We came back, improved the design and added new features. ... Next time we went back, the ophthalmologist used the device to take images of 20 patients and gave us feedback on the quality of images. In the next rounds, the ophthalmologist continued to take images of patients and showed us how our images compared with images from the high-end devices from international vendors."

\section{Opportunities Set by Context: Regulation, Cognition and Norms}


Our study suggests that the observed testing approach in India was enabled by the local context in India: its regulatory flexibility, the cognitive orientation of the development teams, and the normative orientation of the physicians.

Regulatory Flexibility: Our analysis suggested that in the case of the MNC R\&D center, testing in the operating room was possible because the surgical jig was not regulated in India. The MNC R\&D center project manager observed, "In India, medical devices, particularly surgical devices, are not regulated." He pointed out, "There was no legal violation in India from our standpoint. We followed all the rules in India while doing the testing in the operating rooms." The emphasis on regulatory flexibility was also evident in the other two projects. Members of both project teams pointed to the fact that the absence of clear regulatory guidelines specific to medical device prototype testing during device development allowed the teams to opt for the iterative, high-fidelity testing approach.

Our validation interviews at later stages revealed that most medical devices in India are not regulated and that there is little formal guidance on the development processes. The Drugs and Cosmetics Act, 1940 is the regulatory framework that applies to the import, development, manufacture, distribution, and sale of drugs and cosmetics in India. Medical devices were initially considered the equivalent of drugs; over time, however, a broad consensus emerged that the Drugs and Cosmetics Act is not appropriate for regulating medical devices. Accordingly, the Medical Devices Regulation Bill was proposed in 2006. This bill, however, had not yet been approved as of 2016. Specifically, relevant to our study is the absence of regulations related to the development of medical devices.

It should be noted that the regulatory aspect is not just limited to the lack of medical device regulations in India; as in many other developing countries, compliance with laws related to testing on human subjects has traditionally been low in India. Moreover, an overburdened judiciary system and lack of awareness of individual rights due to poverty and low education levels create an environment that reduces litigation risk for physicians. This situation stands in stark contrast to the significantly high number of litigations related to medical devices in developed countries like the US.

Our discussions with medical-device development experts in the US underscored that the regulatory environment in India is significantly different from that of the US. Early-stage experimentation and testing practices in US medical device development do not use humans 
and clinical settings. All early-stage concept validation and refinements are based on animal or bench testing to avoid any risk to human subjects, real or perceived. Once a product concept is established, early-stage feasibility testing is conducted per strict regulatory guidelines. ${ }^{1}$

Thus, testing in med-device development in the US is linear and sequential in nature and shaped by a focus on patient safety and a desire to minimize legal risk and liability. In some cases, especially for startups or high-risk devices, it can be hard to find a physician/hospital to partner with, and it is not uncommon for patients to refuse participation in a study. Further, if the learning from testing calls for significant changes to the original concept, the development team must loop back to rework the concept refinement and validation and then redo feasibility testing.

Proposition 2: An emerging economy's regulatory flexibility (like India's) allows both international and local organizations to adopt an iterative, high-fidelity testing approach while developing medical devices. This approach contrasts with the relatively linear and sequential testing approach adopted in developed countries like the US.

Cognitive Orientation: Our study suggests that the iterative testing observed was feasible due to the mindset of the product development team members. The Director of the US MNC R\&D center observed, "Most of our staff are engineering graduates who are either fresh from school or have joined us from the software industry. They do not have prior experience in developing medical devices." Our interactions with the three project teams showed that though they had little to no medical device development experience, they had significant exposure to software development methodologies like "Agile" and "Scrum" that encourage iterative testing. This lack of medical device development experience, along with the absence of established methodologies and regulated environment, led the development teams to adopt an iterative approach.

Our argument that the team's mindset resulting from limited experience, the absence of formalized processes, and awareness of iterative software development methodologies

\footnotetext{
${ }^{1}$ Early-stage feasibility requires (1) receipt of Investigational Device Exemption (IDE) clearance from the FDA (or is generated by the development team in certain cases), (2) identification of a clinical partner for further testing and signing off on a clinical trial agreement between the legal representatives of the development team and the clinical partner, (3) approval from an IRB after providing specific details such as study hypothesis, background, aims, outcomes being measured, methodology, safety, and (4) finally receiving consent from each individual patient.
} 
allowed the teams to adopt iterative, high-fidelity testing approach is consistent with prior research (Bazerman and Watkins, 2004; Katz and Allen, 1982; Levitt and March, 1988) that suggests that the inertia, rigidity, and biases resulting from a firm's dominant logic (Prahlad and Bettis, 1986) and experiences can be disadvantageous in novel and uncertain environments. We argue that the idea of dominant logic applies not just to the firm but also to groups/functions within the firm. In the cases studied, the limited prior experience with product development efforts and the absence of established logic, methodologies, end-to-end processes, and a regulated environment freed up the teams from a rigid, dominant mode of experimentation and testing. Specifically, in these projects we saw the development teams introduce early-stage prototypes in clinical settings with the aim of learning from the high-fidelity setting and iteratively improving the design. For example, a senior developer of the ICU software development team observed, "Once we had the approval from the senior physicians that we could use the ICU on an ongoing basis (to observe, test, learn), we knew that we could take an incremental approach and develop the solution over multiple cycles."

The reliance on iterative testing for feedback was also enabled by the teams' perhaps naive assessment that the risks to patients from early-stage prototypes were minimal and manageable, and thus that formal IRB approval and patient consent weren't always necessary. While explaining why no IRB approval was needed or patient consent taken, the project manager at the US MNC R\&D center observed, "We took all the safety precautions and it was almost impossible that any patient would be affected." Moreover, the ICU software development team did not seem to be concerned that its development work would pose a risk to the patient. The standard explanation was that there was no risk as they did not change the treatment protocol or staffing levels. These assessments across projects highlight a common perception of risk management and individual patient rights in India that is in sharp contrast to that in the US; our study suggests that this perception in India has likely been exacerbated by the generally harsh and resource-constrained realities of the emerging market environment, limited awareness of and attention to human subject experimentation protocols, and the absence of clear guidelines driving medical device development.

Proposition 3: The cognitive orientation of medical device development teams at both international and local organizations in an emerging economy (like India) contributes to adopting an iterative testing approach in high-fidelity settings. 
Normative Orientation: The support and involvement of physicians in India based on their values and norms were critical in ensuring the feasibility of the testing approach adopted by the project teams. The behavior of physicians across the cases suggests that the physicians interacting with medical device development teams considered local medical device development efforts as not only necessary but also desirable and therefore were actively engaged in supporting such development efforts. Thus, we highlight the normative orientation of the physicians as key to enabling the observed iterative, high-fidelity testing. In the case of the MNC team, surgeons were excited about the possibility that the planned device would reduce the surgical process complexity and improve clinical outcomes. The project manager observed, "We worked with leading surgeons in India and they had no lack of opportunities. The reason they got engaged with us is largely their passion for developing devices for the local market." A similar theme was reflected in the ophthalmology device project manager's comment, "The hospital was aware that the number of preventable blindness cases was very big in India and the numbers were increasing dramatically. The greatness of the organization was that they gave us time believing that we may be able to do something."

In our discussions with physicians at other hospitals, we observed a growing recognition that for affordable healthcare to be accessible to large numbers of people in India, medical devices like those in the cases studied had to be designed and manufactured locally. We also consistently heard that early-stage low-risk testing of devices is supported by many medical practitioners in India, given their desire to gain access to devices that are affordable and appropriate for the Indian market and the belief that devices developed by MNCs in and for affluent countries will not address the needs of the India market. One surgeon commented, "As long as someone brings a reasonable new product idea to me that will help my patients, I am ready to work with him to try it out in the operating room."

The orientation and action of the physicians in India stood in stark contrast to those of physicians in the US. The US medical device experts we talked to pointed out that US physicians would be very unlikely to participate in similar testing activities given the prevailing regulatory and ethical guidelines and the severe penalties for violating them. 
Proposition 4: The normative orientation of key stakeholders (e.g., hospital administrators, physicians) in an emerging economy (like India) can allow medical device development teams access to high-fidelity test environments.

\subsection{Impact on the Nature of Learning}

High-Fidelity Settings: The ability to test prototypes iteratively in high-fidelity settings resulted in deep learning. Our analysis of project testing documents revealed that during the $\mathrm{MNC}$ project's first prototype iteration, the blocks on the femur and tibia did not fit well because osteophytes (bone deformities) were impinging. Moreover, the team identified a need to redesign the jig for the tibia by adding a chamfer (rocket cut). A third field test pointed to the need for further modification of the jig profile to avoid impingement on soft tissues on the bone. No one realized the need for these design changes during the saw-bone sessions, as the saw-bone models lacked soft tissue, or in other words were of lower fidelity. Similarly, the fifth study highlighted the need to increase the surface area of the jigs to allow the surgeons to get an easy grip.

Further, the team emphasized the advantages of the operating room as a testing environment over the cadaver labs used in the US. The R\&D center head commented, "One of the key things about evaluating whether the product will work is to put the jig on knee bones and see if it fits. You cannot do it on one bone and say it is done. It is only possible through the variation of bones you study. ... But cadavers in cadaver labs often do not have knee problems.

So even though we may spend a lot of time and money on testing with cadavers in the US, what we design is often not accurate." He observed that the development of a surgical jig with cadavers would have likely required numerous expensive design corrections during later clinical testing - when changes are frowned upon given the significant work, time, and costs involved.

The initial iterations at the eye hospital allowed the ophthalmology device startup team to recognize issues with image quality and operator ease-of-usability. Commenting on the usefulness of the iterative approach in improving image quality, a key member of the startup observed, "Some of the early stage development of the optical system could be done using an artificial eye (model of the human eye). However, the later-stage development could not be done using artificial eyes as the real patient eye is needed to get a feel for the quality of the 
images and to validate whether ophthalmologists can use the images." The startup team acknowledged that given their limited background in ophthalmology and device development, it would have been extremely hard, if not impossible, to develop the internal lens and lighting arrangement without repeated testing in a real setting. Similarly, the team developing the ICU software explained that being able to test different product versions and features in the operating context (with multiple doctors, nurses, and patients) led to rich learning and accelerated development.

We acknowledge that learning from such an iterative testing approach would be beneficial for any product development effort irrespective of location. However, we argue that in the case of product development in emerging economies, the observed approach is particularly impactful given limited experience, resources, infrastructure, and ecosystem access. In all three cases, the development teams had no clear picture of the final design at the outset of the project. Learning from iterative testing allowed them to take the necessary decisions early and avoid expensive revisions later, thus likely driving down the development timeline and costs.

Analogous Learning: A review of the project documents and our interviews showed that iterative testing also provided a broad set of insights on product use protocols and workflows. An ophthalmology project member observed, "While testing the device at the hospital, we realized the satellite clinics of the hospital are connected via a wireless LAN network and also that each of these clinics had two computers. This allowed us to think through how the nurse at the remote clinic can use our device along with the computer to take images of the patient eye and share the images with an ophthalmologist at the main hospital. The patient can then talk to the ophthalmologist over video-conference. Today we have four of these satellite clinics using our device."

Similarly, a member of the MNC R\&D center team observed, "As we worked with surgeons at different hospitals, we observed the variation in the specification and quality of CT scans and realized the need to have a standardized protocol for the scans we were going to use as input for developing the device." The observed variation in the specification and quality of CT scans reflects the absence of strict standards across medical centers in India. The iterative interactions with surgeons also allowed the team to better understand the end-to-end workflow at the hospital and design the device delivery and operating room surgical protocol. The team 
emphasized that insights into surgeon preferences, process flow, and surgical protocols were unlikely to emerge from testing in cadaver labs.

Proposition 5: Iterative testing of medical device prototypes in high-fidelity settings by product development teams in an emerging economy (like India) results in deeper and accelerated learning.

\section{Discussion and Conclusion}

The local context in India drove medical device development teams toward learning from rapid, high-fidelity, iterative prototype-based testing. Of course, we acknowledge that such learning would benefit product developers irrespective of location. But the novelty of our study's findings is about the 'contextual facilitators': the regulatory, normative and cognitive elements of India's emerging economy context. Conversely, our study is also about the context of developed economies like the US that prohibits such a testing-based learning approach and instead requires medical device development teams to adopt a more linear, sequential, and conservative testing approach with a focus on patient safety, standardized guidelines, and legal risks.

\subsection{Research Implications}

Our findings contribute to existing research in three ways. First, we shed light on previously un(der)-explored product development processes in emerging economies and on why and how teams adopt an iterative testing approach to learn. Thus, our study provides new insights into the processes underlying the design uncertainty resolution process during the development of emerging economy innovations and thereby builds on the recent but rapidly developing body of work on emerging economy innovation. For example, our findings complement recent research that studies various types of innovation in emerging economies (Zeschky et al., 2014), explores the relevance of these innovations in developed countries (Govindarajan and Ramamurti, 2011), and identifies mechanisms critical for building and sustaining effective business models for emerging economy innovations (Winterhalter et al., 2017). Specifically, our study highlights that in addition to the lower product cost of emerging economy innovations like cost-innovation and frugal-innovation, the process of developing these innovations is itself often frugal and severely limited by resources and capabilities. 
Moreover, recent discussions on reverse innovation suggest that developed country MNCs should engage in innovation in emerging economy markets to develop winning products for developed country markets. This paper suggests that an advantage of reverse innovation might be accelerated uncertainty resolution during product development thanks to easy access to highfidelity test settings.

Second, we describe how the normative, cognitive, and regulatory context influences testing activities in India and thereby highlight that the emerging economy context can enable and support product development activities; the local context is not necessarily a challenge. Furthermore, our study offers a contextual perspective of critical product development processes. This context-based process perspective is consistent with extensive discussions on the impact of external context on a firm's strategy, structure, processes, and performance in various management theories such as contingency theory (Lawrence and Lorsch, 1967), resource-dependence theory (Pfeffer and Salancik, 1978), population ecology (Hannan and Freeman, 1977) and institutional theory (North, 1990; Scott, 1995). The fundamental idea here is that for firms to be successful, they must align their logic, structures, and processes to the external environment. Our study suggests that the observation on the importance of alignment with the external context holds true also for product development processes in emerging economies, given the unique local context.

Third, our study has implications for understanding the locus of innovation. Today MNCs routinely use product development teams distributed across locations (Boutellier et al., 1998; Pearce and Papanastassiou, 1996). Prior work in global product development has emphasized macro-factors like resource availability, agglomeration benefit, and market access as critical determinants of the decision about global product development center location (for detailed references, please see Alcacer and Delgado, 2012). This paper suggests that MNCs might benefit from considering locations that are conducive to early and accelerated learning through better testing. This idea of context-enabled iterative testing is also relevant for entrepreneurship and lead-user innovation, especially in the presence of high novelty, where iterative testing is essential (von Hippel, 1987; Lüthje and Herstatt, 2004).

\subsection{Practical Implications}


Emerging economies are known for harsh business environments, and organizations often grapple with how to address their contextual challenges (Khanna and Papelu, 2005). However, the emerging economy context is not entirely restrictive or negative, and our study suggests that practitioners need to recognize that some aspects of the context might facilitate an organization's innovation activities and design their processes accordingly.

A related takeaway is the need to contextualize global product development systems and processes. Specifically, firms should be judicious when trying to replicate elements from established best practices in developed economies. A one-size-fits-all approach can result in suboptimal outcomes and frustration, as "best" practices often fail to transfer well between developed and developing countries (Kogut and Singh, 1988; Kostova and Zaheer, 1999). Finally, it is important to acknowledge that the iterative, high-fidelity testing approach will be effective even in developed countries due to the associated rich learning.

\subsection{Policy Implications}

Policymakers should consider the influence of regulatory frameworks on product development practices critical to entrepreneurship and innovation. This is especially true in cases in which prior experience, resources, and access (as in the ability to pay) are severely limited, as in the Indian medical device industry. The global standardization of regulatory frameworks and processes could have a disparate influence on patient cost and access. In our study, we observed that more flexibility provided more opportunities to respond to the inadequate supply (or in some cases, the complete absence) of appropriate and affordable medical devices in emerging economies. At the same time, ethical considerations need to be factored in. In the projects we studied, teams took additional steps to ensure that patient safety was not compromised, yet one cannot ex-ante guarantee that the steps taken are adequate, and even if they are, that other innovators will behave responsibly. It is beyond the scope of this paper to present a clear and definitive policy framework, but the debate on appropriate policy frameworks to encourage innovation needs to be informed by the challenges, such as testing, that companies face in trying to bring a low-cost medical device to market.

\subsection{Future Research}


Our study puts forward several interesting research questions. First, it suggests the need for future research to further explore emerging economy innovation project processes beyond prototyping and to study prototype-based testing for other products in other emerging economies (e.g., China). This would allow us not only to broaden our current understanding of product development practices but also to identify unique and critical processes underlying emerging economy innovation efforts. Second, there is a need to further explore the idea of context-based product development practices and their impact on product development performance, given that the current body of research on product development has largely been formed in developed countries (the US, Western Europe, and Japan) and lacks a contingency perspective. Third, further studies are necessary to explore how extant research related to the locus of innovation (e.g., global R\&D center location, user innovation, innovation-oriented entrepreneurship, etc.) can benefit from considering the role of the external context in the uncertainty resolution process. Finally, we acknowledge the need for further studies to inform policy makers of how to balance societal needs for healthcare access with population safety considerations.

\subsection{Limitations}

This study has several limitations. First, we realize that exploratory findings cannot always be generalized across industries and countries. As is usually the case with inductive exploratory studies, our intent was to obtain deep insights into processes (in this case, those underlying medical device innovations in emerging economies) before conducting broader validation studies. We encourage researchers to build on our findings and study other settings. Second, we cannot disentangle the effects of the three contextual dimensions discussedcognitive, normative and regulative — on the adoption of iterative testing, as these dimensions are typically interrelated. For example, cognitive frameworks drive normative values, normative values influence regulative guidelines, and regulative guidelines in turn influence both cognitive frameworks and normative values. We encourage researchers to pursue welldesigned studies to identify the impact of each dimension. Third, and finally, we recognize that our exploratory study design and methods do not allow us to claim a causal effect of context on product development performance. Future research based on larger project datasets is needed. 
Table 1: Data Collection \& Validation

\begin{tabular}{|c|c|c|c|c|}
\hline & $\begin{array}{c}\text { Initial Exploratory } \\
\text { Interviews }\end{array}$ & $\begin{array}{c}\text { Interviews Focused on } \\
\text { Medical Device } \\
\text { Development Project } \\
\end{array}$ & $\begin{array}{c}\text { Archival Data on } \\
\text { Medical Device } \\
\text { Development } \\
\text { Project } \\
\end{array}$ & $\begin{array}{c}\text { Discussions to } \\
\text { Validate Findings* }\end{array}$ \\
\hline $\begin{array}{l}\text { Ophthalmology } \\
\text { Startup }\end{array}$ & 2 & 6 & \multirow{3}{*}{$\begin{array}{l}\text { Reviewed project } \\
\text { documents to collect } \\
\text { data on project scope, } \\
\text { team, timeline, } \\
\text { activities, project } \\
\text { plans, design files, } \\
\text { product testing }\end{array}$} & 2 \\
\hline $\begin{array}{l}\text { Tertiary Care } \\
\text { Hospital }\end{array}$ & 2 & 5 & & 3 \\
\hline $\begin{array}{l}\text { US MNC } 1 \\
\text { R\&D Center }\end{array}$ & 3 & 8 & & 3 \\
\hline $\begin{array}{l}\text { Medical } \\
\text { Supplies and } \\
\text { Furniture } \\
\text { Startup } \\
\end{array}$ & 2 & \multirow{2}{*}{\multicolumn{2}{|c|}{$\begin{array}{l}\text { Declined to share project details citing } \\
\text { confidentiality concerns }\end{array}$}} & 1 \\
\hline $\begin{array}{l}\text { European } \\
\text { MNC R\&D } \\
\text { Center }\end{array}$ & 2 & & & 1 \\
\hline $\begin{array}{l}\text { US MNC } 2 \\
\text { R\&D Center }\end{array}$ & \multicolumn{4}{|c|}{ Declined participation given lack of management bandwidth to participate in research project } \\
\hline
\end{tabular}


Table 2: Exploratory Study Findings

\begin{tabular}{|c|c|c|c|c|c|}
\hline Findings & Explanation & $\begin{array}{l}\text { Case 1: Ophthalmology } \\
\text { Device by Startup }\end{array}$ & $\begin{array}{l}\text { Case 2: ICU Software by } \\
\text { Hospital }\end{array}$ & $\begin{array}{l}\text { Case 3: Orthopedic } \\
\text { Surgical Jig by MNC } \\
\text { R\&D Center }\end{array}$ & Other Sources $^{2}$ \\
\hline $\begin{array}{l}\text { Constraints } \\
\text { Set by } \\
\text { Context }\end{array}$ & $\begin{array}{l}\text { The emerging } \\
\text { economy context } \\
\text { creates challenges for } \\
\text { medical device } \\
\text { development projects. } \\
\text { These challenges } \\
\text { relate to lack of } \\
\text { experience with } \\
\text { R\&D, resources, } \\
\text { infrastructure, } \\
\text { ecosystem and access } \\
\text { to and involvement of } \\
\text { physicians. }\end{array}$ & $\begin{array}{l}\text { "Had we been from a large } \\
\text { established company, we would } \\
\text { know a lot about customer } \\
\text { expectations. But in our case } \\
\text { that was not true. All of us have } \\
\text { different backgrounds. Nobody } \\
\text { is from ophthalmology, nobody } \\
\text { is into medical devices } \\
\text { seriously." - Team member } \\
\text { It was extremely difficult for } \\
\text { the startup to hire or partner } \\
\text { with individuals having the } \\
\text { necessary ophthalmology } \\
\text { background as such talent was } \\
\text { rare. Further, being a startup, } \\
\text { they had limited access to } \\
\text { clinicians and patients and } \\
\text { therefore customer input was a } \\
\text { challenge. - Field notes }\end{array}$ & $\begin{array}{l}\text { "As a hospital, our experience } \\
\text { and capabilities of developing } \\
\text { medical devices are limited. } \\
\text { At the same time, XYZ (the } \\
\text { partnering software company) } \\
\text { has not developed clinical } \\
\text { products in the past." - } \\
\text { Project manager } \\
\text { Even though there were } \\
\text { several successful software } \\
\text { companies in India, most had } \\
\text { no experience of developing } \\
\text { clinical software that involved } \\
\text { complex activities like patient } \\
\text { condition monitoring and } \\
\text { treatment plan development. } \\
\text { Typically, few of these } \\
\text { companies had worked on } \\
\text { developing systems focused } \\
\text { on hospital administration and } \\
\text { management. - Field notes }\end{array}$ & $\begin{array}{l}\text { "We looked for a cadaver } \\
\text { lab to partner with but did } \\
\text { not find any. The cadaver } \\
\text { labs we came across did not } \\
\text { have any experience in } \\
\text { partnering with medical } \\
\text { device companies and did } \\
\text { not have the infrastructure } \\
\text { necessary for the work we } \\
\text { wanted to do." - Team } \\
\text { member }\end{array}$ & $\begin{array}{l}\text { "Doctors in India are } \\
\text { always seeing patients. } \\
\text { They do not have time to } \\
\text { do research or block } \\
\text { days to collaborate with } \\
\text { medical device } \\
\text { companies." - Project } \\
\text { manager at India R\&D } \\
\text { center of European } \\
\text { medical device MNC }\end{array}$ \\
\hline $\begin{array}{l}\text { 2. Role of } \\
\text { Context in } \\
\text { Enabling } \\
\text { Iterative } \\
\text { Prototyping } \\
\text { (a) Regulator } \\
\text { y } \\
\text { Flexibility } \\
\text { in India }\end{array}$ & $\begin{array}{l}\text { Absence of clearly } \\
\text { defined regulatory } \\
\text { guidelines allowed } \\
\text { medical device teams } \\
\text { to iteratively test } \\
\text { prototypes in high- } \\
\text { fidelity clinical } \\
\text { settings from the } \\
\text { early stages of the } \\
\text { development effort. }\end{array}$ & $\begin{array}{l}\text { "The fact that there we did not } \\
\text { have to follow too many } \\
\text { external rules and regulations } \\
\text { made things easier for us. We } \\
\text { could do what we needed to do } \\
\text { to get the product launched." - } \\
\text { Project manager }\end{array}$ & $\begin{array}{l}\text { "The hospital ethics } \\
\text { committee approved the } \\
\text { study. We did not need any } \\
\text { external approvals." - Team } \\
\text { member }\end{array}$ & $\begin{array}{l}\text { "We could not have taken } \\
\text { such an approach in the US } \\
\text { given FDA requirements, } \\
\text { our own design controls, } \\
\text { expectations from and } \\
\text { concern of the medical } \\
\text { community, patient consent, } \\
\text { worries about litigation, } \\
\text { etc." - Director, R\&D } \\
\text { center }\end{array}$ & $\begin{array}{l}\text { "Decisions to allow a } \\
\text { device to be tested or not } \\
\text { are decided primarily by } \\
\text { doctors in the hospital, } \\
\text { often in consultation } \\
\text { with the administrative } \\
\text { team. In my } \\
\text { understanding there are } \\
\text { no external guidelines." } \\
\text { - Senior administrator at } \\
\text { an Indian hospital }\end{array}$ \\
\hline 2. Role of & Absence of rigid & "We did not ask for patient & ICU patients often have high & "When we started we had & A lot of the workforce \\
\hline
\end{tabular}

\footnotetext{
physicians at hospitals in India and also the later-stage discussions with two medical device development experts in the US.

2 These include preliminary exploratory interviews with medical device development teams in initially shortlisted companies (not related to case studies) and 


\begin{tabular}{|c|c|c|c|c|c|}
\hline Findings & Explanation & $\begin{array}{l}\text { Case 1: Ophthalmology } \\
\text { Device by Startup }\end{array}$ & $\begin{array}{l}\text { Case 2: ICU Software by } \\
\text { Hospital }\end{array}$ & $\begin{array}{l}\text { Case 3: Orthopedic } \\
\text { Surgical Jig by MNC } \\
\text { R\&D Center }\end{array}$ & Other Sources $^{2}$ \\
\hline $\begin{array}{l}\text { Context in } \\
\text { Enabling } \\
\text { Iterative } \\
\text { Prototyping } \\
\text { (b) Cognitive } \\
\text { Orientatio } \\
\text { n of the } \\
\text { Product } \\
\text { Developm } \\
\text { ent Teams }\end{array}$ & $\begin{array}{l}\text { mindset, influence of } \\
\text { established software } \\
\text { development } \\
\text { methodologies and an } \\
\text { optimistic assessment } \\
\text { of risk to patients } \\
\text { allowed the medical } \\
\text { device development } \\
\text { teams to adopt an } \\
\text { iterative prototype- } \\
\text { based testing } \\
\text { approach. }\end{array}$ & $\begin{array}{l}\text { consent as the device is non- } \\
\text { invasive." - Project manager }\end{array}$ & $\begin{array}{l}\text { risk given their condition. } \\
\text { However, the development } \\
\text { team, both physicians and } \\
\text { software developers, did not } \\
\text { seem to be at all concerned } \\
\text { about any additional risk to } \\
\text { patient due to the } \\
\text { development efforts. The } \\
\text { standard response was that } \\
\text { they did not change the } \\
\text { treatment protocol or affect } \\
\text { staffing levels and there was } \\
\text { no reason to be concerned. - } \\
\text { Field notes }\end{array}$ & $\begin{array}{l}\text { not decided on a fixed } \\
\text { number of iterations. The } \\
\text { initial thought was we will } \\
\text { do a few of these and see } \\
\text { how we are progressing. It } \\
\text { is all based on the } \\
\text { development speed, what } \\
\text { the surgeons are saying at } \\
\text { each round and then us } \\
\text { doing back and forth." - } \\
\text { Project manager }\end{array}$ & $\begin{array}{l}\text { who are hired to develop } \\
\text { medical devices come } \\
\text { from the software } \\
\text { industry. Software is big } \\
\text { as an industry in India } \\
\text { and there has been very } \\
\text { little in terms of medical } \\
\text { device industry or device } \\
\text { development training } \\
\text { schools traditionally in } \\
\text { India. Thus, the medial } \\
\text { device developers are } \\
\text { aware of development } \\
\text { approach based on } \\
\text { iterative testing - Field } \\
\text { notes }\end{array}$ \\
\hline $\begin{array}{l}\text { 2. Role of } \\
\text { Context in } \\
\text { Enabling } \\
\text { Iterative } \\
\text { Prototyping } \\
\text { (c) Normative } \\
\text { Orientatio } \\
\text { n of the } \\
\text { Physicians }\end{array}$ & $\begin{array}{l}\text { Strong preference of } \\
\text { physician community } \\
\text { for locally developed, } \\
\text { affordable and } \\
\text { context-appropriate } \\
\text { medical devices } \\
\text { allowed med-device } \\
\text { development teams to } \\
\text { access high-fidelity } \\
\text { clinical settings for } \\
\text { iterative testing of } \\
\text { prototypes. }\end{array}$ & $\begin{array}{l}\text { "We never had to pay the } \\
\text { hospital or doctors for their } \\
\text { time and support. In fact, when } \\
\text { we visited them for testing our } \\
\text { device, they allowed us to stay } \\
\text { at the hospital guest-house. } \\
\text { They appreciated that we were } \\
\text { trying to develop a solution for } \\
\text { a really big problem and were } \\
\text { very supportive." - Startup } \\
\text { founder }\end{array}$ & $\begin{array}{l}\text { "This will help in solving a } \\
\text { big challenge nurses face in } \\
\text { the ICU. While treating } \\
\text { patients, should nurses be } \\
\text { focusing on patient treatment } \\
\text { or maintaining charts?" - } \\
\text { Project member } \\
\text { "Most hospitals in India face } \\
\text { a shortage of well-trained } \\
\text { staff in the ICU in India. To } \\
\text { ensure proper care and reduce } \\
\text { the load on staff, we need } \\
\text { devices like this." - Hospital } \\
\text { physician involved in project }\end{array}$ & $\begin{array}{l}\text { "The surgeons liked the } \\
\text { device as it would make } \\
\text { surgery less complicated, } \\
\text { lead to better outcomes and } \\
\text { also allow less-experienced } \\
\text { surgeons to operate } \\
\text { successfully. Moreover, } \\
\text { being manufactured in } \\
\text { India, it will be a lot more } \\
\text { affordable." - Project } \\
\text { manager } \\
\text { "From the beginning, the } \\
\text { surgeons were very } \\
\text { encouraging. They kept } \\
\text { pushing us that let's try this } \\
\text { out in a surgery. They said } \\
\text { make a bio-compatible part } \\
\text { and we can check it out } \\
\text { during a surgery." - Project } \\
\text { manager }\end{array}$ & $\begin{array}{l}\text { "Doctors are much more } \\
\text { accessible here } \\
\text { compared to US. We can } \\
\text { talk to them frequently } \\
\text { and at very short notice } \\
\text { and that helps us in } \\
\text { making fast progress. In } \\
\text { US, we need to wait for } \\
\text { weeks at times to meet } \\
\text { the doctor and get } \\
\text { feedback." - Project } \\
\text { manager at India R\&D } \\
\text { center of European } \\
\text { medical device MNC }\end{array}$ \\
\hline $\begin{array}{l}\text { 3. Learning } \\
\text { from } \\
\text { Iterative } \\
\text { Prototyping: }\end{array}$ & $\begin{array}{l}\text { The rich learning } \\
\text { from the iterative } \\
\text { prototype-based } \\
\text { testing in a high- }\end{array}$ & $\begin{array}{l}\text { "Initially we used to accept all } \\
\text { patients randomly for imaging. } \\
\text { Later on when we were looking } \\
\text { for inputs from diabetic }\end{array}$ & $\begin{array}{l}\text { "By having access to multiple } \\
\text { patients, nurses and doctors in } \\
\text { the ICU, we were able to } \\
\text { identify and resolve }\end{array}$ & $\begin{array}{l}\text { "We realized during early } \\
\text { iterations that accounting } \\
\text { for bone deformities during } \\
\text { the 3D model development }\end{array}$ & \\
\hline
\end{tabular}




\begin{tabular}{|c|c|c|c|c|c|}
\hline Findings & Explanation & $\begin{array}{l}\text { Case 1: Ophthalmology } \\
\text { Device by Startup }\end{array}$ & $\begin{array}{l}\text { Case 2: ICU Software by } \\
\text { Hospital }\end{array}$ & $\begin{array}{l}\text { Case 3: Orthopedic } \\
\text { Surgical Jig by MNC } \\
\text { R\&D Center }\end{array}$ & Other Sources ${ }^{2}$ \\
\hline $\begin{array}{l}\text { (a) Learning } \\
\text { due to } \\
\text { Higher- } \\
\text { Fidelity } \\
\text { Settings } \\
\end{array}$ & $\begin{array}{l}\text { fidelity clinical } \\
\text { setting accelerates the } \\
\text { product development } \\
\text { process and reduces } \\
\text { the probability of } \\
\text { later-stage rework. } \\
\text { Given the significant } \\
\text { challenges } \\
\text { experienced by PD } \\
\text { projects in these } \\
\text { markets, the learning } \\
\text { from high-fidelity } \\
\text { settings is } \\
\text { fundamental to the } \\
\text { development of } \\
\text { innovative medical } \\
\text { devices in emerging } \\
\text { economies. }\end{array}$ & $\begin{array}{l}\text { retinopathy specialists, we } \\
\text { determined that it is better to } \\
\text { get images of patients having } \\
\text { diabetic retinopathy." - Team } \\
\text { member } \\
\text { "Reading an eye image is a } \\
\text { subjective process. If we give } \\
10 \text { images to five individuals, } \\
\text { the five of them will rate the } \\
\text { image qualities differently. } \\
\text { That is why we needed inputs } \\
\text { from ophthalmologists and the } \\
\text { repeated inputs from multiple } \\
\text { ophthalmologists at the hospital } \\
\text { were very helpful in improving } \\
\text { the image quality." - Project } \\
\text { manager } \\
\text { "In one of our later iterations } \\
\text { we noticed that the operator at } \\
\text { the hospital was having } \\
\text { difficulty in aligning and } \\
\text { focusing the device. We had to } \\
\text { retrain him but we also added a } \\
\text { feature called guided focus } \\
\text { which indicates to the operator } \\
\text { when the focusing is right." - } \\
\text { Project manager }\end{array}$ & $\begin{array}{l}\text { differences amongst the } \\
\text { clinical team on how certain } \\
\text { information needs to be } \\
\text { processed and reported. This } \\
\text { is much harder to do and } \\
\text { sometimes impossible when } \\
\text { we try to get design } \\
\text { requirements and feedback in } \\
\text { individual physician offices. } \\
\text { Partly it is because the } \\
\text { doctors are so busy and partly } \\
\text { it is hard for them to explain } \\
\text { all the details when we are in } \\
\text { their offices." - Team } \\
\text { member } \\
\text { "See, doctors have little time } \\
\text { for us as we are in a busy } \\
\text { hospital, but also we like } \\
\text { being in a busy hospital as it } \\
\text { is great to see differences } \\
\text { across many patient cases. } \\
\text { This helps us decide on what } \\
\text { we need to develop." - Team } \\
\text { member }\end{array}$ & $\begin{array}{l}\text { from the CT scans [...] } \\
\text { would allow the } \\
\text { manufactured jig to be } \\
\text { positioned perfectly on } \\
\text { patient bone. This } \\
\text { realization would have been } \\
\text { harder if we were using } \\
\text { cadavers (as cadaver knees } \\
\text { often are not representative } \\
\text { of knee-surgery patients." - } \\
\text { Director, R\&D center } \\
\text { The surgeons involved are } \\
\text { very well-reputed and busy. } \\
\text { It would have been hard to } \\
\text { get these surgeons, located } \\
\text { in different cities, to come } \\
\text { to a cadaver lab for a day or } \\
\text { two, even if there was a } \\
\text { cadaver lab, as they would } \\
\text { not want to stop their daily } \\
\text { patient related work Thus it } \\
\text { was critical to learn from } \\
\text { the surgeons in the } \\
\text { operating rooms. - Field } \\
\text { notes }\end{array}$ & \\
\hline $\begin{array}{l}\text { 3. Learning } \\
\text { from } \\
\text { Iterative } \\
\text { Prototyping: } \\
\text { (b) Setting } \\
\text { Specific } \\
\text { Analogous } \\
\text { Learning }\end{array}$ & $\begin{array}{l}\text { The frequent iterative } \\
\text { testing process in } \\
\text { clinical settings } \\
\text { allows the product } \\
\text { development teams to } \\
\text { observe the } \\
\text { physicians and nurses } \\
\text { and overall clinical } \\
\text { environment closely. } \\
\text { This, in turn, allows } \\
\text { the team to take early } \\
\text { actions focused on }\end{array}$ & $\begin{array}{l}\text { "Each time we trained an } \\
\text { operator in the field, we } \\
\text { improved our training manual } \\
\text { based on that experience. We } \\
\text { also developed some training } \\
\text { videos." - Project manager } \\
\text { "If we had tested the device in } \\
\text { our office, we would not have } \\
\text { worried about portability till } \\
\text { much later. By having to take } \\
\text { our product to the hospital (in }\end{array}$ & $\begin{array}{l}\text { The testing approach in the } \\
\text { hospital allowed for learning } \\
\text { and initial work related to } \\
\text { integration of the software } \\
\text { with other existing hospital IT } \\
\text { systems. - Field notes }\end{array}$ & $\begin{array}{l}\text { After discussions with the } \\
\text { surgeons, the team decided } \\
\text { to engrave the patient } \\
\text { identifier (patient name, } \\
\text { date of surgery, right or left } \\
\text { leg, etc.) on the jig to avoid } \\
\text { any quality issues. - Field } \\
\text { notes referring to risk of } \\
\text { using device on wrong knee } \\
\text { "When we looked at the } \\
\text { internal processes at the }\end{array}$ & $\begin{array}{l}\text { This kind of analogous } \\
\text { learning happens much } \\
\text { later in more developed } \\
\text { countries like the US. } \\
\text { The access to and } \\
\text { activities in clinical } \\
\text { settings are narrowly } \\
\text { focused on product } \\
\text { efficacy and safety. User } \\
\text { protocols typically are } \\
\text { done at a much later } \\
\text { stage. - Field note based }\end{array}$ \\
\hline
\end{tabular}




\begin{tabular}{|c|c|c|c|c|c|}
\hline Findings & Explanation & $\begin{array}{l}\text { Case 1: Ophthalmology } \\
\text { Device by Startup }\end{array}$ & $\begin{array}{l}\text { Case 2: ICU Software by } \\
\text { Hospital }\end{array}$ & $\begin{array}{l}\text { Case 3: Orthopedic } \\
\text { Surgical Jig by MNC } \\
\text { R\&D Center }\end{array}$ & Other Sources ${ }^{2}$ \\
\hline & $\begin{array}{l}\text { improving the } \\
\text { product ease-of-use } \\
\text { and the fit with the } \\
\text { end-to-end clinical } \\
\text { workflows. }\end{array}$ & $\begin{array}{l}\text { another city) and rural areas for } \\
\text { hospital-led eye-camps we were } \\
\text { able to test the portability of the } \\
\text { device." - Team member }\end{array}$ & & $\begin{array}{l}\text { hospitals, we decided to } \\
\text { hand over the jig to the } \\
\text { hospital the day before the } \\
\text { surgery so that it could be } \\
\text { sterilized before using." - } \\
\text { Project manager }\end{array}$ & $\begin{array}{l}\text { on discussion with } \\
\text { medical device } \\
\text { development experts in } \\
\text { the US }\end{array}$ \\
\hline
\end{tabular}

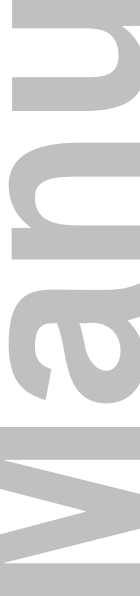




\section{REFERENCES}

Alcacer, J. and Delgado, M. (2012) Spatial organization of firms: internal and external agglomeration economies and location choices through the value chain. Harvard Business School Working Paper, 2012.

Bazerman, M. and Watkins, M. (2004) Predictable Surprises: The Disasters You Should Have Seen and How to Prevent Them. Boston, MA: Harvard Business Review Press.

Boehm, B., Gray, T. and Seewaldt, T. (1984) Prototyping versus specifying: a multiproject experiment. IEEE Transactions on Software Engineering, May, 290-302.

Bogers, M. and Horst, W. (2014) Collaborative prototyping: cross-fertilization of knowledge in prototype-driven problem solving. Journal of Product Innovation Management, 31(4), 744-764.

Boutellier, R., Gassmann, O., Macho, H. and Roux, M. (1998) Management of dispersed product development teams: the role of information technologies. $R \& D$ Management, 28(1), 13-25.

Brown, T. (2009) Change by Design: How Design Thinking Transforms Organizations and Inspires Innovation. New York: Harper Business.

Burgess, S. M. and Steenkamp, J. B. E. (2006) Marketing renaissance: how research in emerging markets advances marketing science and practice. International Journal of Research in Marketing, 23(4), 337-356.

Callahan, J. \& Lasry, E. (2004) The importance of customer input in the development of very new products. $R \& D$ Management, 34(2), 107-120.

Dubiel, A. and Ernst, H. (2013) Success factors of new product development for emerging markets. In The PDMA Handbook of New Product Development (3rd ed.), ed. K. Kahn, S. E. Kay, G. Gibson, and S. Urban, 100-14. New York: John Wiley \& Sons.

Eisenhardt, K. M. (1989) Building theories from case study research. Academy of Management Review, 14, 532-550.

Ernst, H., Kahle, H.N., Dubiel, A., Prabhu, J. and Subramaniam, M. (2015) The antecedents and consequences of affordable value innovations for emerging markets. Journal of Product Innovation Management, 32(1), 65-79.

Gadiesh, O., Leung, P., and Vestring, T. (2007) The battle for China's good-enough market. Harvard Business Review 85(9), 81-89.

Govindarajan, V. and Ramamurti, R. (2011) Reverse innovation, emerging markets, and global strategy. Global Strategy Journal, 1(3-4), 191-205.

Hang, C.-C., Chen, J. and Subramanian, A. M. (2010) Developing disruptive products for emerging economies: lessons from Asian cases. Research-Technology Management, 53(4), 21-26.

Hannan, M. T. and Freeman, J. (1977) The population ecology of organizations. American Journal of Sociology, 82(5), 929-964.

Iansiti, M. (1998) Technology Integration: Making Critical Choices in a Dynamic World. Boston, MA: Harvard Business Review Press.

Katz, R. and Allen, T. J. (1982) Investigating the Not Invented Here (NIH) syndrome: a look at the performance, tenure, and communication patterns of $50 \mathrm{R} \&$ D Project Groups. Product Development Management, 12(1), 7-20.

Khanna, T. and Palepu, K. G. (2005) Spotting institutional voids in emerging markets. Harvard Business School Background Note 106-014, August.

Khanna, T., Palepu K. G. and Sinha, J. (2005) Strategies that fit emerging markets. Harvard Business Review 83(6), 63-76.

Krishnan, V., Eppinger, S. D. and Whitney, D. E. (1997) A model-based framework to overlap product development activities. Management Science, 43(4), 437-451.

Kogut, B. and Singh, H. (1988) The effect of national culture on the choice of entry mode. Journal of International Business Studies, 19(3), 411-432.

Kostova, T. and Zaheer, S. (1999) Organizational legitimacy under conditions of complexity: the case of the multinational enterprise. Academy of Management Review, 24(1), 64-81. 
Lawrence, P. R. and Lorsch, J. W. (1967) Organisation and Environment. Homewood, IL: Irwin.

Lee, Y., Lin, B.-W., Wong, Y.-Y. and Calantone, R. J. (2011) Understanding and managing international product launch: a comparison between developed and emerging markets. Journal of Product Innovation Management, 28(1), 104-20.

Levitt, B. and March, J. G. (1988) Organizational learning. Annual Review of Sociology, 14, 319-340.

London, T. and Hart, S. L. (2004) Reinventing strategies for emerging markets: beyond the transnational model. Journal of International Business Studies, 35(5), 350-370.

Luo, Y. (2001) Determinants of entry in an emerging economy: a multilevel approach. Journal of Management Studies, 38(3), 443-72.

Lüthje, C. \& Herstatt, C. (2004) The Lead User method: an outline of empirical findings and issues for future research. $R \& D$ Management, 34(5), 553-568.

Mair, J. and Marti, I. (2009) Entrepreneurship in and around institutional voids: a case study from Bangladesh. Journal of Business Venturing, 24(5), 419-435.

Mair, J., Martí, I. and Ventresca, M. J. (2012) Building inclusive markets in rural Bangladesh: how intermediaries work institutional voids. Academy of Management Journal, 55(4), 819-850.

Mascitelli, R. (2000) From experience: harnessing tacit knowledge to achieve breakthrough innovation. Journal of Product Innovation Management, 17(3), 179-193.

Miles, M. B. and Huberman, A. M. (1994) Qualitative Data Analysis: An Expanded Sourcebook. Sage.

North, D. C. (1990) Institutions, Institutional Change, and Economic Performance. Cambridge, MA: Harvard University Press.

Pearce, R. \& Papanastassiou, M. (1996) R\&D networks and innovation: decentralised product development in multinational enterprises. $R \& D$ Management, 26(4), 315-333.

Peng, M. W., Wang, D. Y. and Jiang, Y. (2008) An institution-based view of international business strategy: a focus on emerging economies. Journal of International Business Studies, 39(5), 920936.

Pfeffer, J. \& Salancik, G. R. (1978) The External Control of Organizations: A Resource Dependence Approach. NY: Harper and Row Publishers.

Pisano, G. (1996) Learning-before-doing in the development of new process technology. Research Policy, 25, 1097-1119.

Prahalad, C. K. (2012) Bottom of the pyramid as a source of breakthrough innovations. Journal of Product Innovation Management, 29(1), 6-12.

Prahalad, C. K. and Bettis, R. A. (1986) The dominant logic: a new linkage between diversity and performance. Strategic Management Journal, 7(6), 485-501.

Prahalad, C. K. and Hammond, A. (2002) Serving the world's poor, profitably. Harvard Business Review, 80(9), 48-59.

Ray, S. and Ray, P. K. (2011) Product innovation for the people's car in an emerging economy. Technovation, 31(5), 216-227.

Schrage, M. (2000) Serious Play: How the World's Best Companies Simulate to Innovate. Boston, MA: Harvard Business School Press.

Scott, W. R. (1995) Institutions and Organizations. Thousand Oaks, CA: Sage.

Sheth, J. N. (2011) Impact of emerging markets on marketing: rethinking existing perspectives and practices. Journal of Marketing, 75(4), 166-82.

Smith, R. P. and Eppinger, S. D. (1997) A predictive model of sequential iteration in engineering design. Management Science, 43(8), 1104-1120.

Terwiesch, C. and Loch, C. H. (2004) Collaborative prototyping and the pricing of custom-designed products. Management Science, 50(2), 145-158.

Terwiesch, C., Loch, C. H. and Meyer, A. D. (2002) Exchanging preliminary information in concurrent engineering: alternative coordination strategies. Organization Science, 13(4), 402-419.

The Economist. (2010) The world turned upside down: a special report on innovation in emerging markets. The Economist, 17 April. 
Thomke, S. (1997) The role of flexibility in the development of new products: an empirical study. Research Policy, 26(1), 105-119.

Thomke, S. H. (1998) Managing experimentation in the design of new products. Management Science, 44(6), 743-762.

Thomke, S., Von Hippel, E. and Franke, R. (1998) Modes of experimentation: an innovation processand competitive - variable. Research Policy, 27(3), 315-332.

Thomke, S. and Fujimoto, T. (2000) The effect of "front-loading" problem-solving on product development performance. Journal of Product Innovation Management, 17(2), 128-142.

Thomke, S. and Bell, D. E. (2001) Sequential testing in product development. Management Science, 47(2), 308-323.

Verganti, R. (1997) Leveraging on systemic learning to manage the early phases of product innovation projects. R\&D Management, 27(4), 377-392.

Von Hippel, E. (1986) Lead users: a source of novel product concepts. Management Science, 32(7), 791805.

Williamson, P. (2010) Cost innovation: preparing for a "value-for-money" revolution. Long Range Planning, 43, 343-353.

Winterhalter, S., Zeschky, M. B., Neumann, L. and Gassmann, O. (2017) Business models for frugal innovation in emerging markets: the case of the medical device and laboratory equipment industry. Technovation, 66, 3-13.

Wright, M., Filatotchev, I., Hoskisson, R. E. and Peng, M. (2005) Strategy research in emerging economies: challenging the conventional wisdom. Journal of Management Studies, 42(1), 1-33.

Yin, R. K. (2013) Case Study Research: Design and Methods. Thousand Oaks, CA: Sage Publications. Zeschky, M., Widenmayer, B. and Gassmann, O. (2011) Frugal innovation in emerging markets. Research-Technology Management, 54(4), 38-45.

Zeschky, M. B., Winterhalter, S. and Gassmann, O. (2014) From cost to frugal and reverse innovation: mapping the field and implications for global competitiveness. Research-Technology Management, 57(4), 20-27.
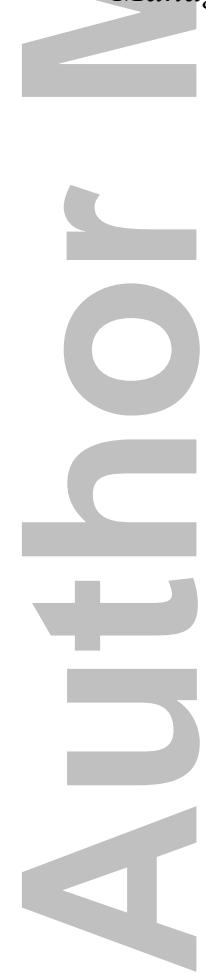


\section{University Library}

\section{- $\mathrm{M}$ IIN E R VA A gateway to Melbourne's research publications}

Minerva Access is the Institutional Repository of The University of Melbourne

Author/s:

Gupta, B;Thomke, S

Title:

An exploratory study of product development in emerging economies: evidence from medical device testing in India

\section{Date:}

2018-09-01

\section{Citation:}

Gupta, B. \& Thomke, S. (2018). An exploratory study of product development in emerging economies: evidence from medical device testing in India. R \& D MANAGEMENT, 48 (4), pp.485-501. https://doi.org/10.1111/radm.12324.

Persistent Link:

http://hdl.handle.net/11343/284009 